\title{
The Comparable Results of Minimally Invasive Therapy versus Primary Anastomosis in the Management of Partial Posterior Urethral Stricture
}

Gede Wirya Kusuma Duarsa ${ }^{1 *}$, Rheny Subnafeu², Anak Agung Gde Oka¹, I. Kadek Budi Santosa ${ }^{1}$, I. Wayan Yudiana ${ }^{1}$, Pande Made Wisnu Tirtayasa ${ }^{1}$, Ida Bagus Putra Pramana ${ }^{1}$, Tjokorda Gede Bagus Mahadewa ${ }^{3}$, Christopher Ryalino ${ }^{4}$

${ }^{1}$ Department of Surgery, Division of Urology, Faculty of Medicine, Udayana University, Bali, Indonesia; ${ }^{2}$ Department of Surgery, Faculty of Medicine, Udayana University, Bali, Indonesia; ${ }^{3}$ Department of Surgery, Division of Neurosurgery, Faculty of Medicine, Udayana University, Bali, Indonesia; ${ }^{4}$ Department of Anesthesiology and Intensive Care, Faculty of Medicine, Udayana University, Bali, Indonesia

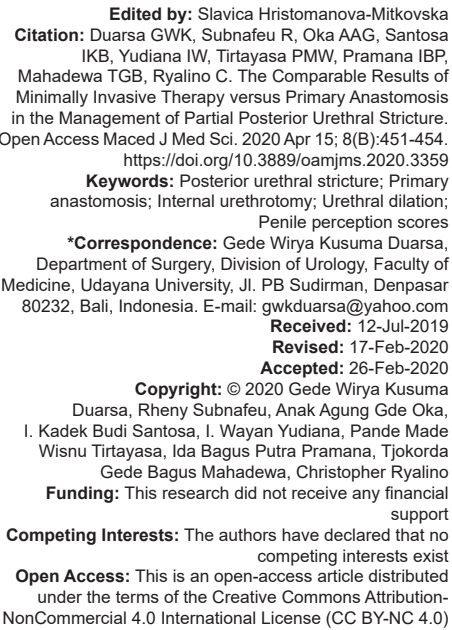

Edited by: Slavica Hristomanova-Mitkovsk Duarsa GWK, Subnafeu R, Oka AAG, Santosa IKB, Yudiana IW, Tirtayasa PMW, Pramana IBP Mahadewa TGB, Ryalino C. The Comparable Results of Minimally Invasive Therapy versus Primary Anastomosis in the Management of Partial Posterior Urethral Stricture. hed $\mathrm{Aed}$ Sci. 2020 Apr 15; 8(B):451-454. Keywords: Posterior urethral stricture; Primary anastomosis; Internal urethrotomy; Urethral dilation Penile perception scores
Pis, Internal ure *Correspondence: Gede Wirya Kusuma Duarsa, Department of Surgery, Division of Urology, Faculty of Medicine, Udayana University, JI. PB Sudirman, Denpasar 80232, Bali, Indonesia. E-mail: gwkduarsa@yahoo.com Received: $12-J u l-2019$ Revised: 17-Feb-2020 Copyright: $\odot 2020$ Gede Wirya Kusuma Duarsa, Rheny Subnafeu, Anak Agung Gde Oka, Kadek Budi Santosa, I. Wayan Yudiana, Pande Made Wisnu Tirtayasa, Ida Bagus Putra Pramana, Tjokorda Gede Bagus Mahadewa, Christopher Ryalino
Gernu Tirtayasa, Id Bagus Putra Pramana, TJoorda Funding: This research did not receive any financial Competing Interests: The authors have declared that no competing interests exis Open Access: This is an open-access article distribute under the terms of the Creative Commons Attribution-
NonCommercial 4.0 International License (CC BY-NC 4.0)

\section{Abstract}

BACKGROUND: Urinary retention has many etiologies. One of them is urethral stricture or the narrowing of urethral lumen due to fibrotic tissue. Urethral stricture is considered a medical emergency condition because it might cause complications in some extent. At present, there are several surgical techniques introduced with their advantages and disadvantages.

AIM: The study aimed to compare the outcome of minimal invasive therapy (MIT) or excision and primary anastomosis (EPA) techniques.

PATIENTS AND METHODS: A retrospective cohort study was performed on patients with partial posterior urethra stricture. The inclusion criteria were all patients with partial posterior urethral stricture who underwent MIT or EPA from 2014 to 2018. The data of International Prostate Symptom Score (IPSS), quality of life (QoL), urinary peak flow rate (Qmax), urine residue, erection hardness score, clean intermittent catheterization $(\mathrm{CIC})$, recurrence, and penile perception scores (PPS) were obtained and analyzed postoperatively.

RESULTS: Thirty-four patients included in the study, consisted of 17 patients for each group. EPA group showed significantly superior to MIT in Qmax ( $<<0.001)$, CIC $(p=0.007)$, and PPS score $(p=0.003)$. However, no significance differences were found in QoL $(p=0.071)$, IPSS score $(p=0.083)$, bladder urine residue $(p=0.688)$ recurrence $(p=0.225)$, and erectile function $(p=0.303)$.

CONCLUSION: EPA may be superior to MIT in some aspect. However, other advantages of MIT could be outweighed EPA techniques, such as QoL, IPSS, bladder urine residual, stricture recurrence, and erectile function. MIT still has a place to be the first-line management of partial posterior urethral stricture.

\section{Introduction}

Urinary retention is the condition whereby someone cannot pass the urine as desired, in which the urine will be collected in the bladder, exceeds its capacity. One of many reasons this condition emerge is the narrowing of urethral lumen due to urethral wall fibrosis or urethral stricture. This condition considered as an emergency due to complications that can arise following urinary retention. This disease should be treated by surgery approach. The typical length of the male urethra is around $20-23 \mathrm{~cm}$ and can be divided into anterior and posterior segments. Anterior urethra includes meatus, fossa navicular, penile urethra, and bulbar urethra. The posterior part consists of the membranous urethra and prostatic urethra [1], [2].

Pelvic fracture urethral injury (PFUI) is the most common condition associated with posterior urethral stricture [2]. There are two methods of treatment in the acute phase of PFUI, the placement of urethral catheter endoscopically, and placement of percutaneous cystostomy. The definitive treatment of posterior urethral stricture is usually performed in 3-6 months after trauma due to the hematoma that has to resolve into fibrotic tissue [3]. The management of urethral stricture depends on the length of the urethral stricture, which consists of minimally invasive techniques (MIT) and urethral reconstruction using stricture excision and primary anastomosis (EPA) technique [4].

This study compared the outcomes of EPA and MIT techniques in patients with partial posterior urethral stricture. The outcomes measured were International Prostate Symptom Score (IPSS), quality of life (QoL), urinary peak flow rate (Qmax), residual urine, clean intermittent catheterization $(\mathrm{CIC})$, erection hardness score (EHS), recurrence, and penile perception scores (PPS). 


\section{Patients and Methods}

This is a retrospective cohort observational study. The number of subjects for each study group was 17 , based on the standard formula used to calculate the study sample. Consecutive sampling was used in this study until a minimum number of subjects were achieved. The study protocol was approved by the Committee of Ethical Research of Udayana University.

The inclusion criteria were all patients with partial posterior urethral stricture (Figure 1) underwent MIT or EPA procedure from 2014 to 2018. The exclusion criteria include incomplete medical records, patients with complete posterior urethral stricture, history of stroke or a spinal disorder, and prolonged immobilization. The outcomes that were measured were IPSS, Qmax, QoL, urinary residue, $\mathrm{CIC}$, EHS, recurrences, and PPS that were taken from the medical records.

Data analysis was using SPSS 21.0 for Windows. All data were presented descriptively where the statistical analysis was performed comparing the outcomes between two groups. Shapiro-Wilk test was used for the normality test to see if the data are normally distributed. Independent t-test, likelihood ratio, Fisher's exact test, and Chi-square test were used for statistical analyses. $p>0.05$ was considered statistically significant.

\section{Results}

The samples in this study were 34 cases, consists of 17 patients treated with each technique (MIT and EPA). The mean age of patients in the EPA and MIT group was 44.2 and 54.3 years, respectively $(p=0.08)$. Table 1 reviewed all the observed variables in this study.

Using the Shapiro-Wilk test, we performed normality tests on numerical data, including age, IPSS, and Qmax on both groups. The comparative analysis was performed according to the Guide to Clinical Management of Benign Prostate Hypertrophy, whereby score $0-7,8-19$, and 20-35 represent mild, moderate, and severe symptoms of IPSS.

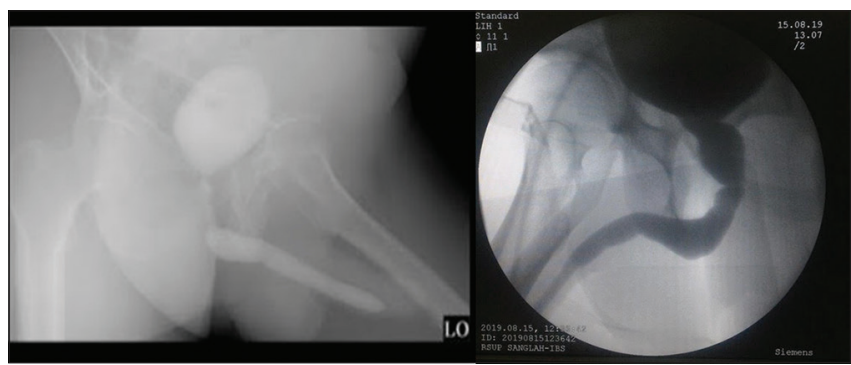

Figure 1: Partial posterior urethral stricture from one of our subjects
Most subjects in EPA (88.2\%) and MIT (58.5\%) group had mild IPSS symptoms. Meanwhile, in terms of QoL, we found no statistically significant difference between the two groups $(p=0.071)$.

We found two variables that were statistically significant in this study. First, the Qmax revealed the rates of 25.5 and $12.4 \mathrm{~mL} / \mathrm{s}$ on EPA and MIT groups, respectively $(p<0.001, \mathrm{Cl} 95 \%=7.721-18.544)$. Second, the PSS of all subjects in the EPA group showed satisfied and very satisfying results, compared to $64.7 \%$ in the MIT group ( $p=0.003$ ).

\section{Discussion}

Several factors take into account deciding the management of urethral strictures, such as its location, previous intervention, and the nature of the disease. In PFUI cases, EPA has shown a success rate of up to 90 [5]. However, this technique has a significant drawback, which is erectile dysfunction (ED). On the other hand, MIT came up with the success rate of around $50 \%$ [5]. Although there is no consensus regarding the acceptable length of urethral stricture to be treated with EPA technique, the surgeon's experience is also being one of the essential factors to consider in the success of management [3].

MIT has been regarded as the first line management in all post-traumatic partial posterior urethral strictures. Morbidity might be avoided in 61\% cases following MIT procedure as compared to EPA. The length of hospital stays, morbidity, complications,

Table 1: Comparison of EPA and MIT in terms of the observed variables

\begin{tabular}{|c|c|c|c|c|}
\hline \multirow[t]{2}{*}{ Variables } & \multicolumn{2}{|l|}{ Group } & \multirow[t]{2}{*}{$p$-value } & \multirow[t]{2}{*}{$\mathrm{Cl} 95 \%$} \\
\hline & $\operatorname{EPA}(n=17)$ & MIT $(n=17)$ & & \\
\hline Age (years), mean \pm SD & $44.2 \pm 15.9$ & $54.2 \pm 16.3$ & $0.080^{\mathrm{a}}$ & \\
\hline IPSS, n (\%) & & & $0.083^{b}$ & \\
\hline Mild $(0-7)$ & $15(88.2)$ & $10(58.8)$ & & \\
\hline Moderate $(8-19)$ & $1(5.9)$ & $6(35.3)$ & & \\
\hline Severe $(20-35)$ & $1(5.9)$ & $1(5.9)$ & & \\
\hline Quality of life, $\mathrm{n}(\%)$ & & & $0.071^{b}$ & \\
\hline Happy & $12(70.6)$ & $6(35.3)$ & & \\
\hline Generally satisfied & $2(11.8)$ & $4(23.5)$ & & \\
\hline Satisfied & $1(5.9)$ & $6(35.3)$ & & \\
\hline Generally not satisfied & $2(11.8)$ & $1(5.9 \%)$ & & \\
\hline Urine residues & & & $0.688^{\circ}$ & \\
\hline Absence & $14(82.4)$ & $12(70.6)$ & & \\
\hline Present & $3(17.6)$ & $5(29.4)$ & & \\
\hline $\mathrm{Qmax}(\mathrm{mL} / \mathrm{s})$, mean $\pm \mathrm{SD}$ & $25.5 \pm 9.0$ & $12.4 \pm 6.3$ & $<0.001^{\mathrm{a}}$ & $7.721-18.544$ \\
\hline CIC, n (\%) & & & $0.007^{d}$ & \\
\hline No & $16(94.1)$ & $8(47.1)$ & & \\
\hline Yes & $1(5.9)$ & 9 (52.9) & & \\
\hline EHS, n (\%) & & & $0.303^{\mathrm{a}}$ & \\
\hline Severe ED & $1(5.9)$ & $5(29.4)$ & & \\
\hline Moderate ED & $2(11.8)$ & $2(11.8)$ & & \\
\hline Mild ED & $1(5.9)$ & $1(5.9)$ & & \\
\hline No ED & $13(76.5)$ & $9(52.9 \%)$ & & \\
\hline Recurrence, $\mathrm{n}(\%)$ & & & $0.225^{\circ}$ & \\
\hline No & $15(88.2)$ & $11(64.7)$ & & \\
\hline Yes & $2(11.8)$ & $6(35.3)$ & & \\
\hline PPS, n (\%) & & & $0.003^{b}$ & \\
\hline Dissatisfied & $0(0.0)$ & $6(35.3)$ & & \\
\hline Satisfied & $17(100)$ & $10(58.8)$ & & \\
\hline Very satisfied & $0(0.0)$ & $1(5.9)$ & & \\
\hline
\end{tabular}


and post-operative recovery was also decreased significantly using MIT procedures [6]. MIT became popular because it was easy to implement and showed good results in the short term, especially in treating short posterior urethral strictures $(<1 \mathrm{~cm})$. However, stricture recurrence was the most crucial obstacle of MIT in the long term. EPA technique mainly requires a skillful surgeon and relatively difficult as compare to MIT technique.

In this study, the improvement of IPSS in EPA and the MIT group was $88.2 \%$ and $58.8 \%$, respectively. Both techniques showed improvement in the IPSS score on patients and also good post-operative results. The previous study by Le et al. [7] showed that there were no significant differences in IPSS score on patients treated with EPA and MIT following partial posterior urethral stricture.

This study showed that the majority of patients treated with EPA had a good QoL (70.6\%), whereas only $35.3 \%$ of patients in the MIT group had a good QoL ( $p=0.071)$.

Qmax represents the condition of whether there is any urinary tract obstruction or not and also reflects bladder strength in voiding mechanism [8], [9]. A previous study revealed that patients' Qmax following EPA and MIT procedure was 13.5 and $14.7 \mathrm{ml} / \mathrm{s}$, respectively ( $p=0.45$ ) [8]. On the contrary, this study showed that the average Qmax on patients in EPA and MIT group was 25.5 and $12.4 \mathrm{ml} / \mathrm{s}$, respectively ( $p$ $<0.001$ ). The different result might be due to the variance of the study's subjects and also the experience of the surgeons who performed the surgery. Bladder residual urine is one of the primary outcome showing the successful following urethral stricture repair. Result was obtained in our study, whereby no residual urine was found in $82.4 \%$ of patients in the EPA group and $70.6 \%$ patients in the MIT group ( $p=0.688$ ). Eventually, all patients will not have normal Qmax compare to normal people due to the rigid fibrotic tissue that cannot stretch against the force on the point of bulbous spongiosum. Moreover, no post-operative stenosis was found, resulting in inconsiderable bladder urine residue among patients in two groups.

$\mathrm{CIC}$ is performed to dilate and maintain the patency of urethra to prevent a recurrence. The success of urethral stricture repair was marked by no additional procedures needed after the primary procedure. In the current study, up to $94.1 \%$ of patients in the EPA group did not use CIC postoperatively. On the other hand, $47.1 \%$ of patients in the MIT group were free from CIC $(p=0.007)$.

Other promising signs of treatment following urethral stricture repair included improvement in IPSS scores, uninterrupted sexual function postoperatively, and reduced post-operative pain. The less tissue damage caused by MIT, the less interruption of the sexual function obtained. This study showed that most of the patients did not experience ED postoperatively in both groups $(p=0.303)$. The patients who experienced $E D$, mostly due to the trauma itself, even before the surgery were performed. This fact might be the reason there were $29.4 \%$ and $5.9 \%$ patients in MIT and EPA group, respectively, who still developed ED post management. Previous studies reported the ED rate of $2.2-10.6 \%$ on patients following MIT procedure. This condition might be due to cavernous nerve injury after MIT, urine extravasation to the periurethral space that causing fibrotic tissue, infection, or by a channel that been made between corpus cavernosum and spongiosum [10], [11], [12].

There was no recurrence in $88.2 \%$ and $64.7 \%$ patients in the EPA and MIT group, respectively $(p=0.225)$. All patients in the EPA group were satisfied with the surgery result, whereas only $58.8 \%$ of patients in the MIT group were satisfied with the result. In the comparison of the patient's satisfaction with the final result, as measured by the PPS score, the EPA group was superior to the MIT group $(p=0.003)$.

In this study, we have proven that MIT procedure has quite similar results as compared to EPA procedure on many aspects such as QoL, IPSS score, urine residue, recurrence, erectile function as assessed by EHS score, Qmax value, and overall satisfaction measured by PPS [13]. By having those results, we showed that MIT procedure is not inferior as compared to EPA in the management of partial posterior urethral strictures in our institution. However, until recently, EPA is still deemed as a gold standard of treatment in the management of posterior urethral strictures in many studies [13], [14]. The results in this study do not attempt to against what has been decided as a gold standard in posterior urethral stricture management.

Some limitations arose in this study. We do not have the data of the density (depth) of posterior urethral stricture due to the shortage of MRI facility in our institution. Another limitation is design-related. This study uses an observational retrospective cohort study design, which has a high probability of bias or unmatched data.

\section{Conclusion}

MIT has a comparable result to EPA technique in the management of partial posterior urethral strictures. No significant difference was found in QoL, IPSS, bladder urine residual, stricture recurrence, and erectile function in both techniques. Apart from excellent results, MIT may consider as the first choice on the management of partial posterior urethral strictures due to its advantages: easier to perform, lower risk of ED, and relatively lower cost. 


\section{References}

1. Akyuz M, Sertkaya Z, Koca O, Caliskan S, Kutluhan MA, Karaman MI. Adult urethral stricture: Practice of Turkish urologists. Int Braz J Urol. 2016;42(2):339-45. https://doi. org/10.1590/s1677-5538.ibju.2014.0672

PMid:27256189

2. Al-Qudah HS, Santucci RA. Extended complications of urethroplasty. Int Braz J Urol. 2005;31(4):315-23. https://doi. org/10.1590/s1677-55382005000400004

PMid:16137399

3. Barratt RC, Bernard J, Mundy AR, Greenwell TJ. Pelvic fracture urethral injury in males-mechanisms of injury, management options and outcomes. Transl Androl Urol. 2018;7 Suppl 1:S2962. https://doi.org/10.21037/tau.2017.12.35 PMid:29644168

4. Bertrand LA, Voelzke BB, Elliott SP, Myers JB, Breyer BN, Vanni AJ, et al. Measuring and predicting patient dissatisfaction after anterior urethroplasty using patient reported outcomes measures. J Urol. 2016;196(2):453-61. https://doi.org/10.1016/j. juro.2016.01.117 PMid:26907509

5. Lucas ET, Koff WJ, Rosito TE, Berger M, Bortolini T, Neto BS. Assessment of satisfaction and quality of life using self-reported questionnaires after urethroplasty: A prospective analysis. Int Braz J Urol. 2017;43(2):304-10. https://doi.org/10.1590/s16775538.ibju.2016.0207

PMid:28128915

6. Burckhardt CS, Anderson KL. The quality of life scale (QOLS): Reliability, validity, and utilization. Health Qual Life Outcomes. 2003;1:60. https://doi.org/10.1186/1477-7525-1-60.

PMid:14613562
7. Le W, Zhou W, Li C, Wu D, Zhang J, Bian C. A preliminary clinical study of endoscopic minimally-invasive surgery in urethral stricture complicated with false passage. Springerplus. 2016;5(1):1457. https://doi.org/10.1186/s40064-016-3137-x PMid:27652033

8. Goel MC, Kumar M, Kapoor R. Endoscopic management of traumatic posterior urethral stricture: Early results and follow up. J Urol. 1997;157(1):95-7. https://doi.org/10.1016/ s0022-5347(01)65295-9

PMid:8976224

9. Hosseini J, Tabassi KT. Surgical repair of posterior urethral defects: Review of literature and presentation of experiences. Urol J. 2008;5(4):215-22.

PMid: 19101893

10. Sangkum P, Levy J, Yafi FA, Hellstrom WJ. Erectile dysfunction in urethral stricture and pelvic fracture urethral injury patients: Diagnosis, treatment, and outcomes. Andrology. 2015;3(3):4439. https://doi.org/10.1111/andr.12015 PMid:25784590

11. Gallegos M. Advances in urethral stricture management F1000Res. 2016;5:2913. PMid:28105329

12. Mundy AR. Management of urethral strictures. Postgrad Med J. 2006;82(970):489-93. PMid:16891437

13. Tinaut-Ranera J, Arrabal-Polo MÁ, Merino-Salas S, NoguerasOcaña M, López-León VM, Palao-Yago $\mathrm{F}$, et al. Outcome of urethral strictures treated by endoscopic urethrotomy and urethroplasty. Can Urol Assoc J. 2014;8(1-2):E16-9. https://doi. org/10.5489/cuaj. 1407

PMid:24454595

14. Gelman J, Wisenbaugh ES. Posterior urethral strictures. Adv Urol. 2015;2015:628107. https://doi.org/10.1155/2015/628107 